\title{
Meiosis and Fertilization of the Japanese Pearl Oyster Eggs at Different Temperature Observed with a Fluorescence Microscope
}

\author{
Akira Komaru, ${ }^{* 1}$ Hirokazu Matsuda, ${ }^{* 2}$ Takashi Yamakawa, ${ }^{* 2}$ \\ and Katsuhiko T. Wada*1 \\ (Received July 8, 1989)
}

\begin{abstract}
The events of meiosis and fertilization in Japanese pearl oyster eggs allowed to develop at different temperatures $\left(18^{\circ} \mathrm{C}, 23^{\circ} \mathrm{C}\right.$, and $\left.28^{\circ} \mathrm{C}\right)$ were investigated with fluorescence microscope. Change of maternal and paternal chromatin of eggs at $23^{\circ} \mathrm{C}$ were as follows. Spawned eggs were at metaphase of first meiosis. Subsequent to sperm penetration most eggs completed first and second meiosis by 15 and 24 min after insemination, respectively. Female and male pronuclei were formed by $30 \mathrm{~min}$ after insemination. The chromatin of male and female pronuclei condensed gradually and were finally observed as two groups of chromosomes. The two groups of chromosomes combined and formed on the metaphas plate for first cleavage. By $62 \mathrm{~min}$ most eggs completed first cleavage.

It was observed at the higher temperature, that the eggs developed faster. Percentages of eggs which showed abnormal chromosome behavior were higher at $18^{\circ} \mathrm{C}$ and $28^{\circ} \mathrm{C}$ than at $23^{\circ} \mathrm{C}$. Asynchronous development of eggs was observed in all temperature groups. Asynchrony of eggs development was more apparent at $18^{\circ} \mathrm{C}$.
\end{abstract}

Since Stanley et $a .^{1}{ }^{1}$ induced triploid oyster Crassostrea virginica, triploids have been produced in a number of molluscan species (See review, Allen") $\left.{ }^{2}\right)$. To establish the efficient procedures for chromosome manipulation such as triploid production, detailed cytogenetic analysis of eggs is necessary. However, few cytogenetic studies of meiosis in the eggs of the Japanenese pearl oyster has been conducted. $^{3)}$ We studied the course of meiotic events and fertilization of pearl oyster eggs developed at $18^{\circ} \mathrm{C}, 23^{\circ} \mathrm{C}$, and $28^{\circ} \mathrm{C}$ with a fluorescence microscope.

\section{Materials and Methods}

Matured Japanese pearl oysters Pinctada fucata martensii were obtained from cultured population in Mie Prefecture, Japan and induced to spawn by raising water temperature from $20^{\circ} \mathrm{C}$ to $28^{\circ} \mathrm{C}$. Eggs from three females were mixed and divided into three groups. Eggs were kept in sea water maintained at either $18^{\circ} \mathrm{C}, 23^{\circ} \mathrm{C}$, or $28^{\circ} \mathrm{C}$, respectively and spermatozoa from one male were added. Eggs were collected at 3 or $5 \mathrm{~min}$ intervals after insemination and fixed with paraformaldehydeglutaraldehyde fixatives $(2 \%$ paraformaldehyde, $2.5 \%$ glutaraldehyde, in $0.1 \mathrm{~m}$ phosphate buffer, $\mathrm{pH} 7.2)$ at $4^{\circ} \mathrm{C}$. After fixation eggs were rinsed twice with $0.1 \mathrm{M}$ phosphate buffer containing $7 \%$ sucrose and stained with DAPI solution ${ }^{4)}$ for $15 \mathrm{~min}$. Then stained eggs were excited with UV light $(365 \mathrm{~nm})$ and their chromosome behavior was observed with a fluorescence microscope.

\section{Results}

\section{Morphological Changes of Chromatin}

As the chromatin in the eggs was intensively stained with DAPI, we could analyze the detailed behavior of maternal and paternal chromosomes from meiosis to first cleavage. The cytoplasm of eggs was also faintly stained. However, it was difficult to observe cytokinesis of first and second meiosis in detail by this method. We describe the tentative following 11 stages of chromatin of eggs during meiosis and cleavage (Fig. 1).

Figs. 1-0 shows unfertilized eggs. The chromosomes of unfertilized eggs were at metaphase

*1 National Research Institute of Aquaculture, Nansei, Mie 516-01, Japan（古扎 明，和田克彦：水䃏 庁意殖研究所).

*2 Fisheries Research Institute of Mie, Hamajima, Shima, Mie 517-04, Japan (松田浩一, 山川! 卓：三 重紧水産技術センター). 

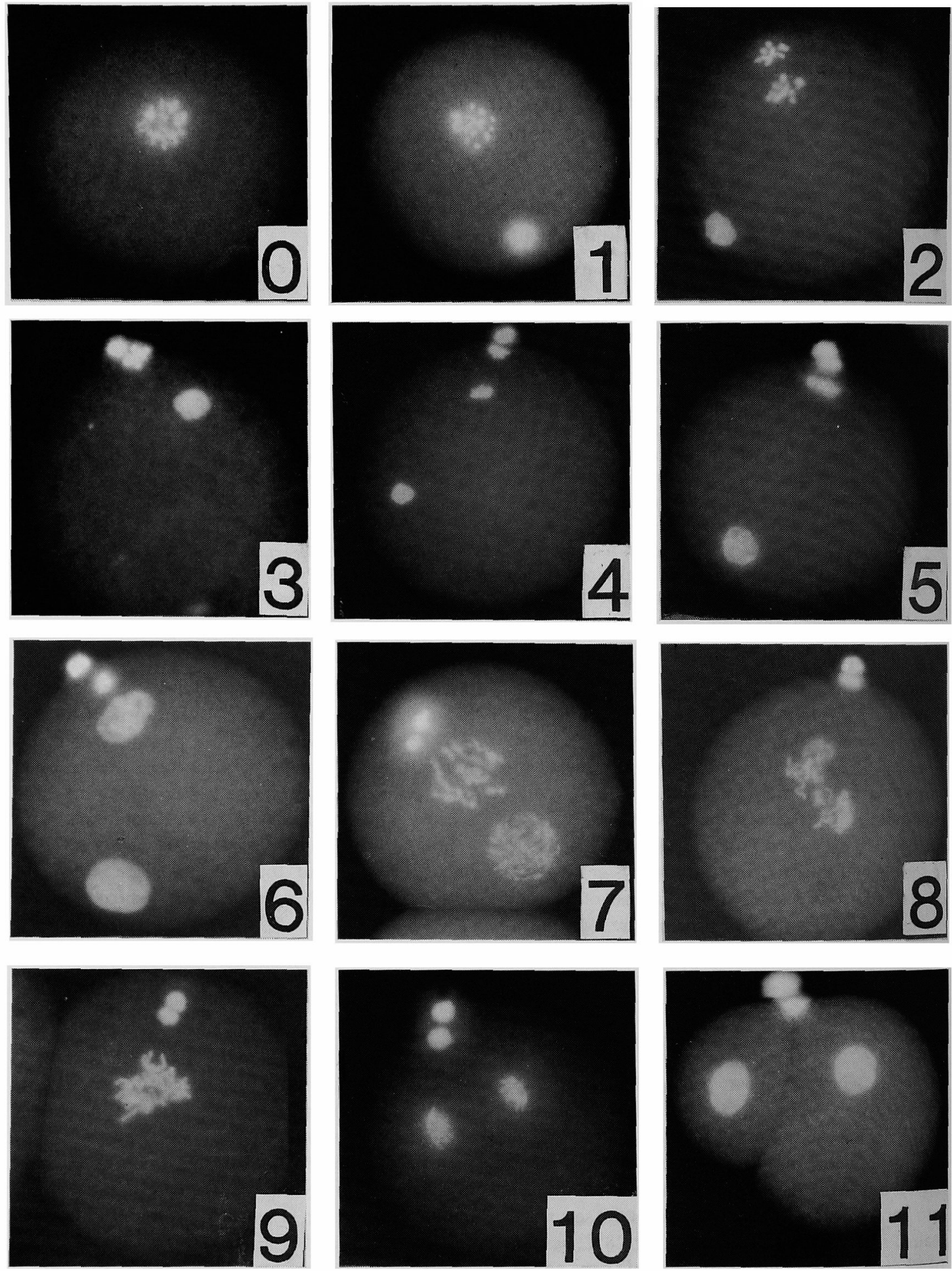

Fig. 1. The events of chromosome behavior from unferilized egg to first cleavage stained with DAPI in the Japanese pearl oyster. 0: Metaphase of first meiosis (Unfertilized egg); 1: Metaphase of first meiosis (Fertilized, Stage 1); 2: Anaphase of first meiosis (Stage 2); 3: Metaphase of second meiosis (First polar body extrusion, Stage 3); 4: Anaphase of second meiosis (Stage 4); 5: Second polar body extrusion (Stage 5); 6: Male and female pronuclei formation (Stage 6); 7: Chromatin condensation of female pronucleus (Stage 7); 8: Chromatin condensation of male pronucleus (Stage 8); 9: Metaphase of first cleavage (Stage 9); 10: Anaphase of first cleavage (Stage 10); 11: Two cell-stage (Stage 11); $(\times 480)$. 
of first meiosis. The contracted bivalents were observed at the periphery of the eggs.

Stage 1 (Fig. 1-1: Metaphase of first meiosis in the fertilized eggs) Male pronucleus has been already started to be enlarged. The bivalents were still at metaphase of first meiosis.

Stage 2 (Fig. 1-2: Anaphase of first meiosis) Two groups of chromosomes at anaphase of first meiosis were observed at the periphery of eggs.

Stage 3 (Fig. 1-3: First polar body formation) The first polar body was observed as a condensed mass of chromatin. The maternal chromosomes remained inside of the eggs formed metaphase of second meiosis near the first polar body.

Stage 4 (Fig. 1-4: Anaphase of second meiosis) Two groups of chromosomes at anaphase of second meiosis were observed beneath the first polar body.

Stage 5 (Fig. 1-5: Second polar body formation) The chromatin of second polar body was contracted and was closed to first polar body. At this stage female pronucleus was faint and irregular.

Stage 6 (Fig. 1-6: Female pronucleus formation) Oval female pronucleus was formed. The size and shape of female pronucleus were similar to male pronucleus. The chromatin of both pronuclei was dispersed.

Stage 7 (Fig. 1-7: Condensation of female pronucleus chromatin) Firstly the female pronucleus chromatin started to condense. However, chromatin of the male pronucleus was still dispersed at this stage.

Stage 8 (Fig. 1-8: Condensation of male pronucleus chromatin) The chromatin of male pronucleus was condensed. Two groups of chromosomes derived from male and female pronuclei were observed. In the present method we could

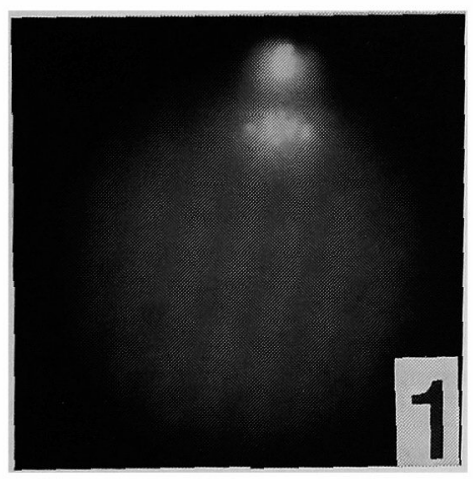

not observe the vesiculation of pronuclear envelopes.

Stage 9 (Fig. 1-9: Metaphase of first cleavage) Two groups of chromosomes derived from both pronuclei combined and formed on the mettaphase plate for first cleavage.

Stage 10 (Fig. 1-10: Anaphase of first cleavage) The chromosomes had moved toward both poles. The cleavage furrow was not still visible.

Stage 11 (Fig. 1-11: 2 cell-stage) Two nuclei and cleavage furrow were observed.

\section{Abnormal Chromosome Behavior in Eggs}

We observed abnormal chromsome behavior of eggs (Fig. 2). Fig. 2-1 shows the unfertilized egg at metaphase of second meiosis withtout male pronucleus (Type A). Fig. 2-2 shows abnormal egg, in which the chromatin of second bolar body was not contracted and remained in the eggs (Type B). These two types of eggs were the majority of the abnormalities observed in this study. The percentage of abnormal eggs of Type $A$ was the

Table 1. Percentages of abnormal eggs at the time when most of eggs were stage 6. Samples were collected at $24 \mathrm{~min}\left(28^{\circ} \mathrm{C}\right), 33 \mathrm{~min}\left(23^{\circ} \mathrm{C}\right)$, and $62 \min \left(18^{\circ} \mathrm{C}\right)$ after insemination

\begin{tabular}{lrrr}
\hline & $28^{\circ} \mathrm{C}$ & $23^{\circ} \mathrm{C}$ & $18^{\circ} \mathrm{C}$ \\
\hline Normal eggs (\%) & 62.9 & 76.8 & 46.6 \\
Abnormal eggs $(\%)$ & 32.9 & 16.8 & 38.2 \\
Type A(\%)*1 & 13.3 & 6.4 & 29.4 \\
Type B $(\%)^{* 2}$ & 11.9 & 4.0 & 5.1 \\
Others (\%) & 7.7 & 6.4 & 3.7 \\
Unfertilized (\%) & 4.2 & 6.4 & 7.4 \\
Total number of & 143 & 125 & 136 \\
eggs observed & & & \\
*1 See Fig. 2-1. & & & \\
*2 See Fig. 2-2. & & &
\end{tabular}

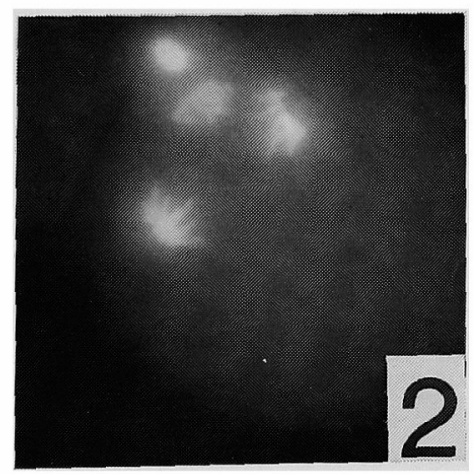

Fig. 2. The abnormal chromosome behavior of eggs. 1: (Type A) The unfertilized egg at metaphase of second meiosis. Male pronucleus was not observed; 2: (Type B) At anaphase of first cleavage the second polar body was not formed and chromatin still remained in the egg; $(\times 480)$. 


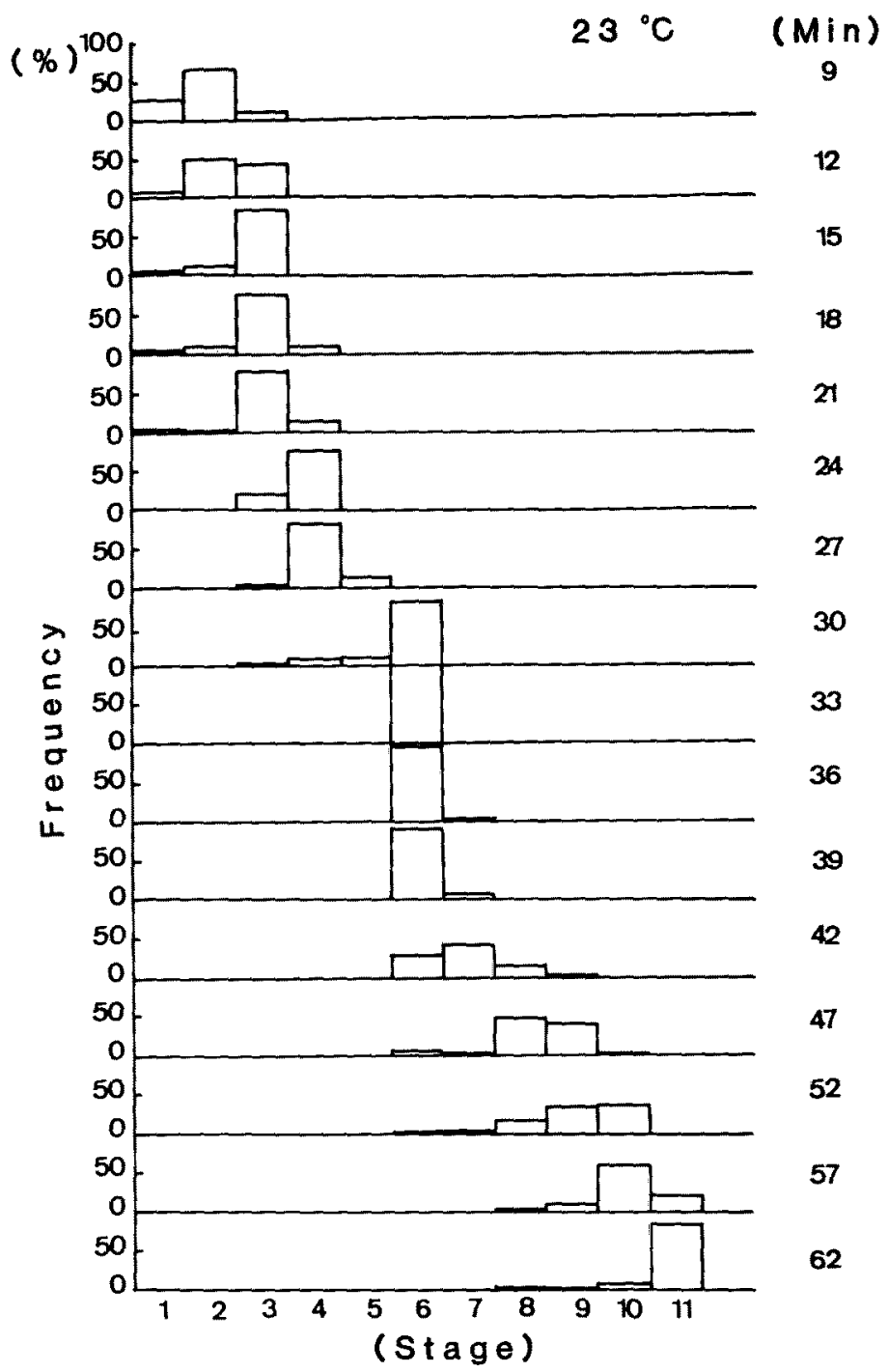

Fig. 3. The frequency distribution of developmental stages (See Fig. 1) of normal eggs developed at $23^{\circ} \mathrm{C}$. Min shows minutes elapsed after insemination. More than 100 eggs were observed in every batch.

highest $(29.4 \%)$ at $18{ }^{\circ} \mathrm{C}$. However, type B was most frequently observed at $28^{\circ} \mathrm{C}(11.9 \%)$.

\section{Asynchronosus Egg Development}

Fig. 3 shows distribution of developmental stages of normal eggs at $23^{\circ} \mathrm{C}$. We observed the asynchronous development during meiosis and first cleavage. For example eggs at anaphase of second meiosis (Stage 4) was observed from $18 \mathrm{~min}$ to 30 min after insemination. This asynchronous development was more apparent at first cleavage (Stage 9: from 42 to $62 \mathrm{~min}$ ).

At the higher temperature, eggs of pearl oyster showed the faster development. Figs. 4-6 show the percentages of eggs developed to anaphase of first meiosis (Fig. 4), anaphase of second meiosis (Fig. 5), and anaphase of first cleavage (Fig. 6) at the three temperatures. The asynchronous development of eggs depended on the temperature. For example at $28^{\circ} \mathrm{C}$ some of eggs completed the second meiosis (Stage 4) at nine min after insemination and almost all eggs reached to this stage at $18 \mathrm{~min}$ (Fig. 5). At $18^{\circ} \mathrm{C}$ some of eggs started second meiosis (Stage 4) at $21 \mathrm{~min}$ and most of eggs completed the second meiosis at $57 \mathrm{~min}$ (Fig. 5). Thus eggs were more asynchronous in timing of meiosis and first cleavage at $18^{\circ} \mathrm{C}$ than $23^{\circ} \mathrm{C}$ and $28^{\circ} \mathrm{C}$. 


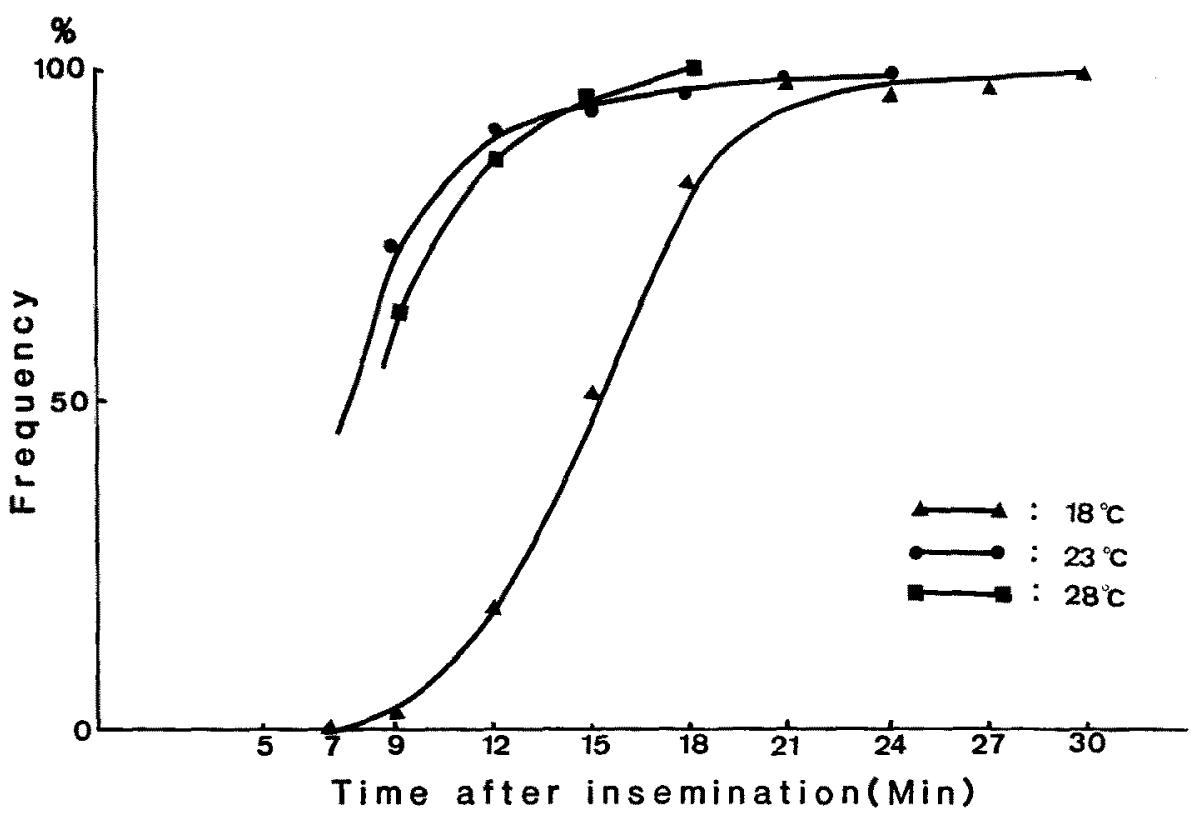

Fig. 4. Percentage of eggs developed to anaphase of first meiosis at three different temperatures.

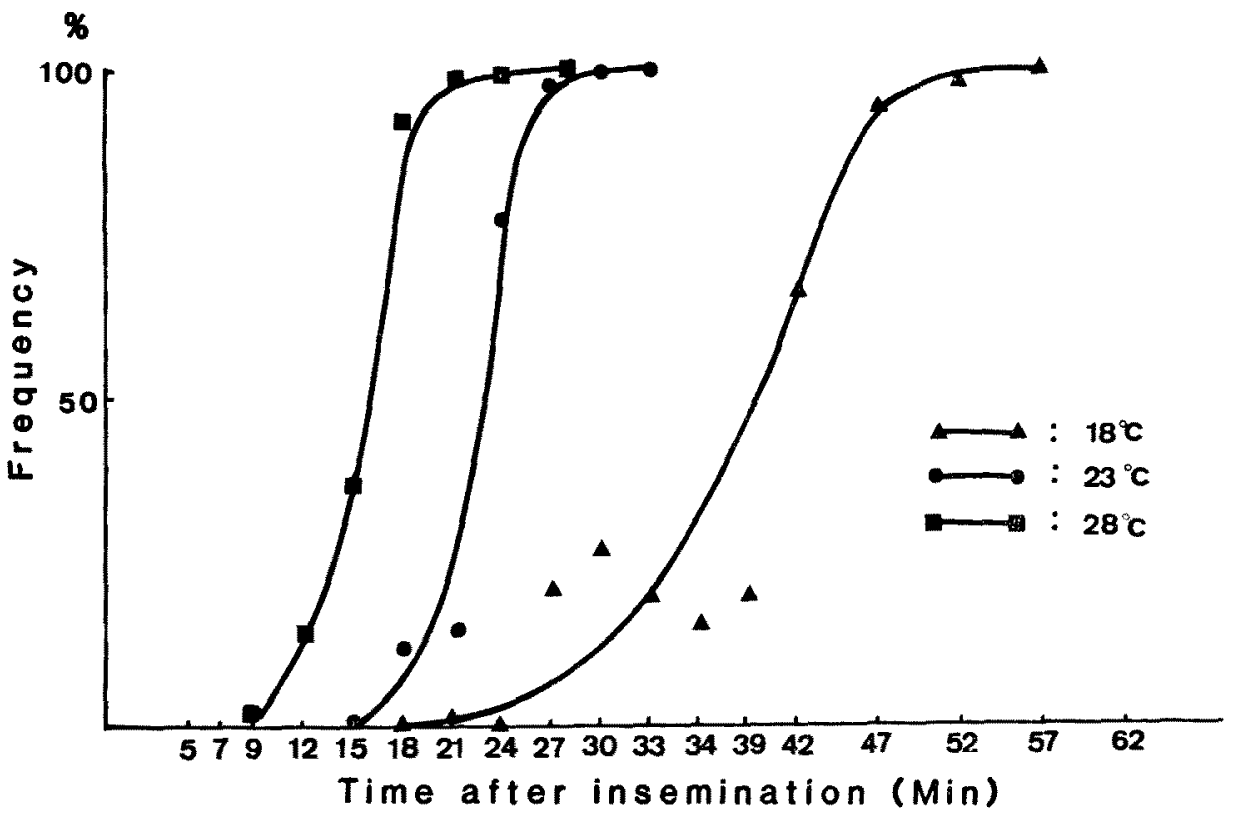

Fig. 5. Percentage of eggs developed to anaphase of second meiosis at three temperatures.

\section{Discussion}

We could observe the changes of maternal and paternal chromatin in the DAPI stained pearl oyster eggs with fluorescence microscope. The method employed in this study is useful to observe detailed events of nuclear changes in the bivalve eggs during meiosis and cleavage.
The events of meiosis and fertilization in pearl oyster eggs were similar to those of Crassostrea virginica, ${ }^{53}$ Crsaaostrea gigas, $\left.{ }^{8}\right)$ and Mytilus edulis, ${ }^{7,8)}$ which were studied by the aceto-orcein squash method, fluorescence microscope, and electron microscope. As Wada ${ }^{3)}$ reported previously, eggs of pearl oyster were fertilized at metaphase of first meiosis and reinitiated meiosis. 


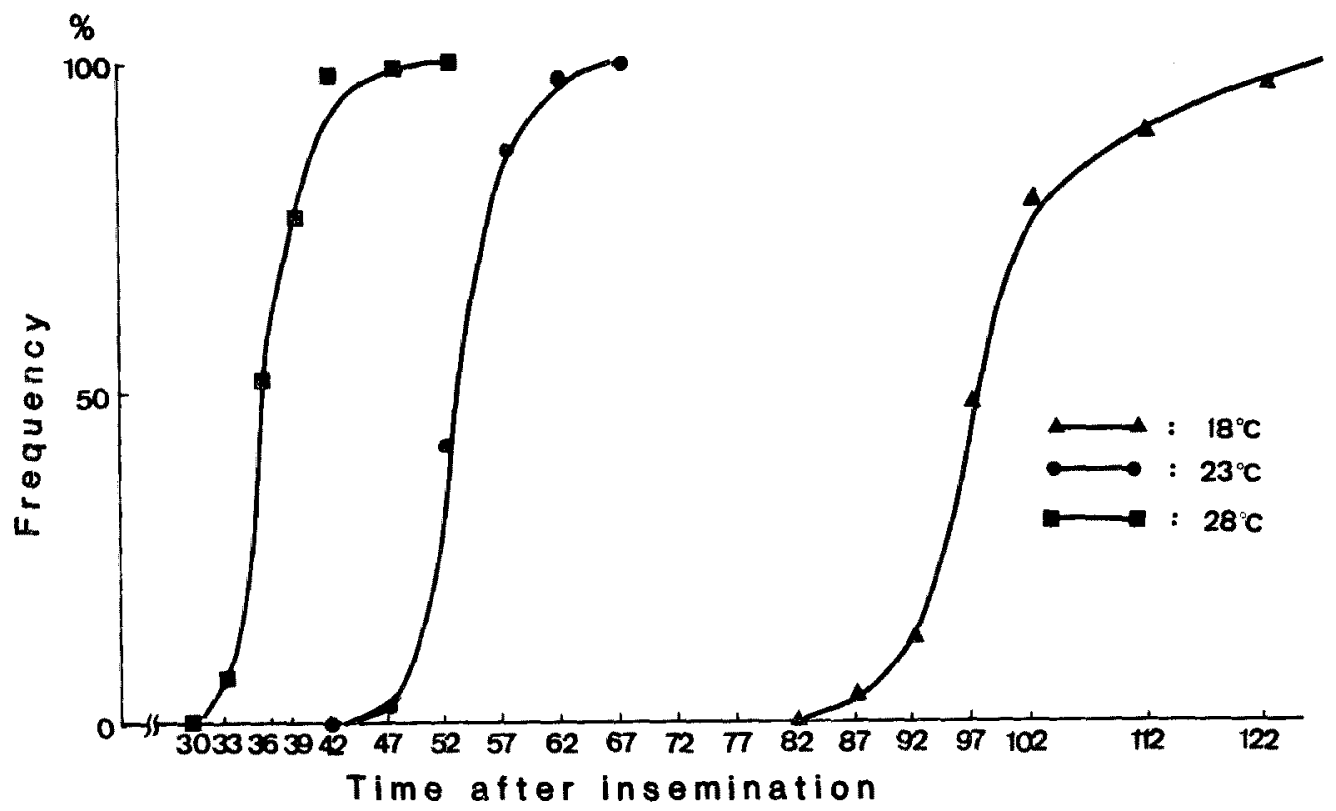

Fig. 6. Percentage of eggs developed to anaphase of first cleavage at three temperatures.

Pearl oyster eggs at male chromatin condensation (Stage 8, Fig. 1-8) seemed to exhibit two groups of chromosomes derived from male and female pronuclei. These two groups of chromsomes combined and formed on the metaphase plate for first cleavage. It seems that zygotes nucleus is not formed in the pearl oyster eggs as reported in Mytilus edulis and Spisula solidissima by Longo and Anderson. ${ }^{7-10}$ As we could not determine when the pronuclear envelopes were vesiculated in the present study, process of pronuclear enlargement of the zygotes should be studied to confirm present observation at light or electron microscopic levels.

At the higher temperature eggs exhibited faster development. Same tendency was also confirmed in Pacific abalone. ${ }^{11}$ However, in this study percentages of abnormal chromosome behavior of eggs at $28^{\circ} \mathrm{C}$ and $18^{\circ} \mathrm{C}$ were higher than that at $23^{\circ} \mathrm{C}$. High or low temperature, or other factor may cause the abnormal chromosome behavior. These results indicate that temperature is important for egg development.

Asynchronous development was observed to some extent at all three temperature groups. For example, at least ten min variation in timing of second meiosis at $23^{\circ} \mathrm{C}$ was detected. This has also been observed in pearl oyster at $25^{\circ} \mathrm{C}$ * As
Downing and Allen ${ }^{12)}$ and Wada et al. ${ }^{13)}$ pointed out, the synchrony of meiotic events of eggs is very important factor when inducing the triploidy in bivalves efficiently. Asynchrony of meiosis as observed in the present study may prevent the induction of all triploid groups.

\section{References}

1) J.G. Stanley, S.K. Allen, and H. Hidu: Aquaculture, 23, 1-10 (1981).

2) S. K. Allen: Proc. World Symp. on Selection, Hybridization, and Genetic Engineering in Aquaculture, Bordeaux 27-30 May, 1986. Vol. II Berlin, 1987 , pp. $127-143$.

3) K. T. Wada: Venus, 35, 9-14, (1976).

4) A. Komaru, Y. Uchimura, H. Ieyama, and K. T. Wada: Aquaculture, 69, 201-209 (1988):

5) A. Longwell and S. Stiles: Caryologia, 21, 65-73 (1968).

6) R. Kurihashi and K. Osanai: Bull. Mar. Biol. Str. Asamushi, Tohoku Univ., 18, 57-65 (1988).

7) F. J. Longo and E. Anderson: J. Exp. Zool, 172, 69-96, (1969).

8) F. J. Longo and A. Anderson: J. Exp. Zool., 172, 97-120, (1969).

9) F. J. Longo and A. Anderson: J. Ultrastructure Research, 33, 495-514, (1970).

10) F. J. Longo and A. Anderson: J. Ultrastructure Research, 33, 515-527, (1970).

11) K. Arai, F. Naito, and K. Fujino: Nippon Suisan Gakkaishi, 52, 417-422, (1986).

12) S. L. Downing and S. K. Allen: Aquaculture, 61, 1-15 (1987).

13) K. T. Wada, A. Komaru, and Y. Uchimura: Aquaculture, 76, 11-19 (1989).

\footnotetext{
* unpublished data.
} 